\title{
The preliminary study on the application of modern advanced processing technique in non-legacy cultural and creative product design-- Taking Wuhu iron painting as an example
}

\author{
Zhang Tiancheng ${ }^{1}$, Chu Tieyi ${ }^{2}$ \\ ${ }^{1}$ School of Art and Design, Anhui Vocational Technical College of Mechanical and Electrical Engineering, Wuhu, Anhui, 241000, China \\ ${ }^{2}$ Wuhu Chushi Iron Painting Craft Co., Ltd., Wuhu, Anhui, 241000, China
}

\begin{abstract}
In order to improve the production efficiency of traditional non-legacy cultural heritages and create non-legacy cultural and creative products in line with modern aesthetics, the paper combines traditional non-legacy cultural heritages manufacturing technique and modern advanced processing technique, which is conducive to improve the design of traditional techniques of Wuhu iron painting. First of all, this paper analyzes the connotation of traditional non-legacy cultural heritage technology, the categories of modern advanced processing technique and the traditional forging technique of Wuhu iron painting, and introduces the strategy and development history of traditional non-legacy cultural heritage manufacturing technique. Taking Baogong cultural and creative product design as an example, this paper innovates the processing technique of iron painting through cutting and processing, and the design theme is fully realized in the innovative iron painting, which to a certain extent realizes the unity of technique and art, and shows the effectiveness and practicability of modern advanced processing technique in non-legacy cultural and creative product design.
\end{abstract}

\section{Preface}

Tradition and modernity have always been the topic in eternal philosophy, and they play the role for marvelous design. From the cautious design in the arts and crafts movement to the bold breakthrough in the Crystal Palace of the World Expo, from the unique warm style in Northern Europe to the high-tech of North America, it shows the characteristics of the times. Every evolution has promoted the development of design. The traditional non-legacy manufacturing technique and modern advanced processing technique can also learn from each other and influence each other. In the design practice, we intend to compare the two techniques, trying to find new design ideas.

In the era of handicraft product design, craftsmen used their wisdom to develop the traditional handicrafts to the greatest extent, and various non-legacy manufacturing techniques emerged one after another. However, in the modern society with the rapid development of science and technology, the traditional non-legacy manufacturing techniques are subject to more and more restrictions. The important reason is that the traditional non-legacy manufacturing technique has low production efficiency, and the aesthetic characteristics it presents are not in line with modern scientific and technological aesthetics. The rapid development of modern science and technology has also made great progress in modern advanced processing technique; the efficient production and concise aesthetic characteristics expressed by modern advanced processing technique, which are in sharp contrast with traditional non-legacy manufacturing techniques. Philosophical principles tell us that the two sides of the contradiction are the whole part of the unity. We can grasp the unity of the opposites and vice versa. How to combine the non-legacy manufacturing technique with modern advanced processing technique is an important topic of this paper. Based on the design of non-legacy cultural and creative products, this paper applies modern advanced processing technique to the improvement of traditional forging technology of Wuhu iron painting. These applications are not only an exploration of cultural and creative product design, but also of great significance to the inheritance and innovation of traditional non-legacy cultural and creative technology and even China's excellent traditional culture.

\section{Traditional non-legacy manufacturing technique}

\subsection{Connotation of traditional non-legacy manufacturing technique}

Intangible cultural heritage refers to all kinds of traditional culture passed down from generation to generation and are regarded as an integral part of their 
cultural heritage, as well as physical objects and places related to traditional culture. According to the definition of the UNESCO Convention for the Protection of Intangible Cultural Heritage, various groups continue to make this intangible culture passed on from generation to generation as their environment, mutual relations with nature and historical conditions changes. At the same time, they have a sense of identity and history, thus promoting cultural diversity and stimulating human creativity. "Intangible cultural heritage" as defined in the Convention includes the following aspects: 1. Oral traditions and forms of expression, including as a medium language of intangible cultural heritage; 2. Performing arts; 3 . Social practice, ceremony, festival activities; 4. Knowledge and practice about nature and the universe; 5 . Traditional handicrafts. The traditional intangible cultural heritage manufacturing techniques mentioned in this paper mainly refer to various manufacturing techniques related to the traditional handicrafts of intangible cultural heritage. It mainly includes the decorative and artistic processing of handmade products, as well as all the techniques and processes. $^{[1]}$

\subsection{Challenges faced by traditional non-legacy manufacturing technique}

Traditional non-legacy manufacturing techniques have existed in farming society for thousands of years, but its foundation has ceased to exist; the traditional non legacy manufacturing techniques cannot meet the needs of modern industrial society. In fact, China's industry in the past hundred years is the transformation from a smallscale peasant society based on handicraft to a large-scale industrial society based on machinery. In such a historical transformation, the traditional non legacy manufacturing technology is bound to become a supporting role in the industrial historical stage or gradually disappear. ${ }^{[2]}$ Under the impact of the wave of science and technology, all kinds of traditional intangible cultural heritage manufacturing techniques are facing many difficulties. It is mainly manifested in two aspects: 1. the production efficiency of the traditional intangible cultural heritage manufacturing techniques is low, which mainly relies on traditional tools and manual labor, and the automation is not enough; 2. the aesthetic characteristics it presents are not in line with modern technological aesthetics to a certain extent. The design circle's call for protection of various traditional nonlegacy manufacturing techniques is increasing, with more strategies emerging.

\subsection{Build better strategy and new "cultural confidence"}

Under the background of the new era, the concept of "cultural and creative industry" has been put forward. For one thing, the non-legacy traditional crafts can have an opportunity to develop and revitalize under new era.
For another, it had the mission to help China establish "cultural self-confidence". Therefore, in recent years, it has been highly concerned and supported by decision makers. ${ }^{[3]}$ The concept of cultural and creative industry is relatively broad, and the design of cultural and creative products in recent years is one of them. A distinctive feature of cultural and creative product design is the integration of tradition and modernity. How to make the traditional intangible cultural heritage manufacturing techniques rejuvenate with new vitality under the new technological background? This is not only the lifeblood of various traditional intangible cultural heritage manufacturing techniques, but also the key for us to build "cultural confidence".

The cultural and creative industry is booming around the world. It is very important to establish national economic development and national image. Cultural creative products need to be inspired by cultural connotation, break through, break through the simple reproduction of the culture, inspire people to find the cultural gene behind the products, and finally achieve the purpose of educating people with culture. The development mode of cultural and creative products exactly coincides with the tangible and material protection of intangible cultural heritage. Through the spread of cultural and creative products, the intangible cultural heritage will be integrated into the daily life of modern people in a diversified material form again, which will play an important role in the protection and inheritance of "non-legacy" traditional crafts. ${ }^{[4]}$

\subsection{Overview of Wuhu iron painting forging techniques}

Since ancient times, Wuhu has developed its iron and steel industry, with the reputation of "any iron that came to Wuhu can be made steel". Wuhu iron painting and forging technology was developed on this basis. Wuhu iron painting uses hammers and forged iron to make exquisite products with superb skills. Wuhu iron painting began in the Kangxi period of Qing Dynasty. It has the simple and capable style and cool artistic characteristics of Xin'an School of painting. It is forged by hand. It is made of wrought iron, heated by a red furnace, and made by forging, drilling, lifting, pressing, welding, filing, chiseling and other techniques. Like other traditional non-legacy manufacturing techniques, Wuhu iron painting forging techniques are facing the pressure of market economy and modern technology. Traditional iron paintings are all forged by hand, with a long learning period and low production efficiency, the aesthetic characteristics presented by them are not accepted by the modern public. In the long-term design practice, the author has been exploring new iron painting processing techniques and art carriers, hoping to find a breakthrough. 


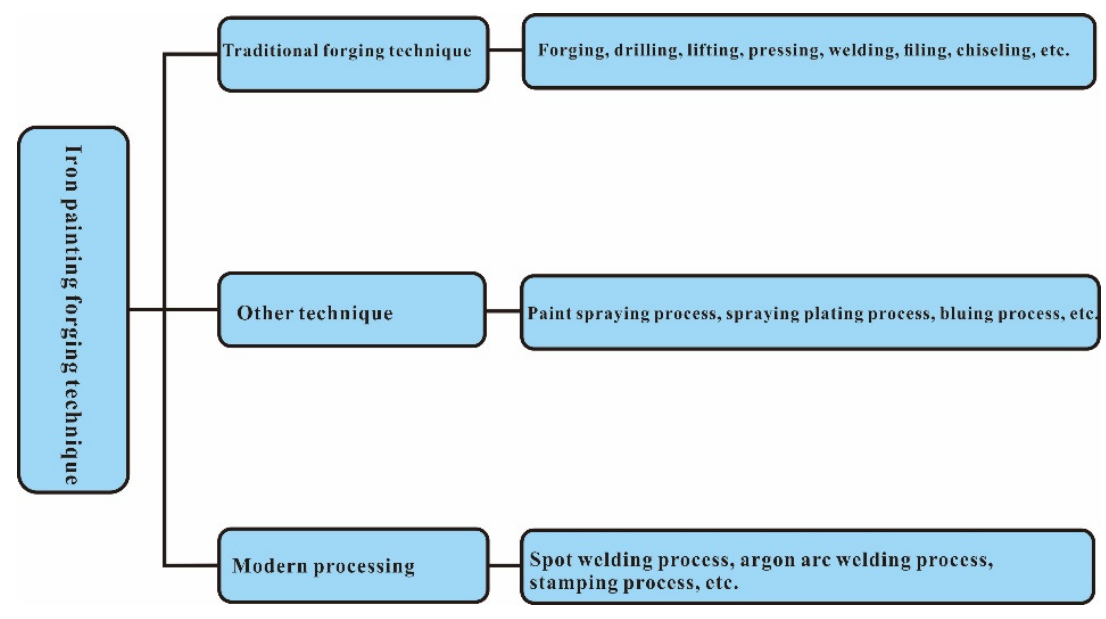

Figure 1. Schematic diagram of iron painting forging technology

From Figure 1, we can see that in the long-term production practice, the forging process of iron painting has introduced some modern processing techniques.

\section{Modern advanced processing technique}

\subsection{The connotation of modern advanced processing technique}

Modern advanced processing technique belongs to advanced manufacturing technology. At present, there is

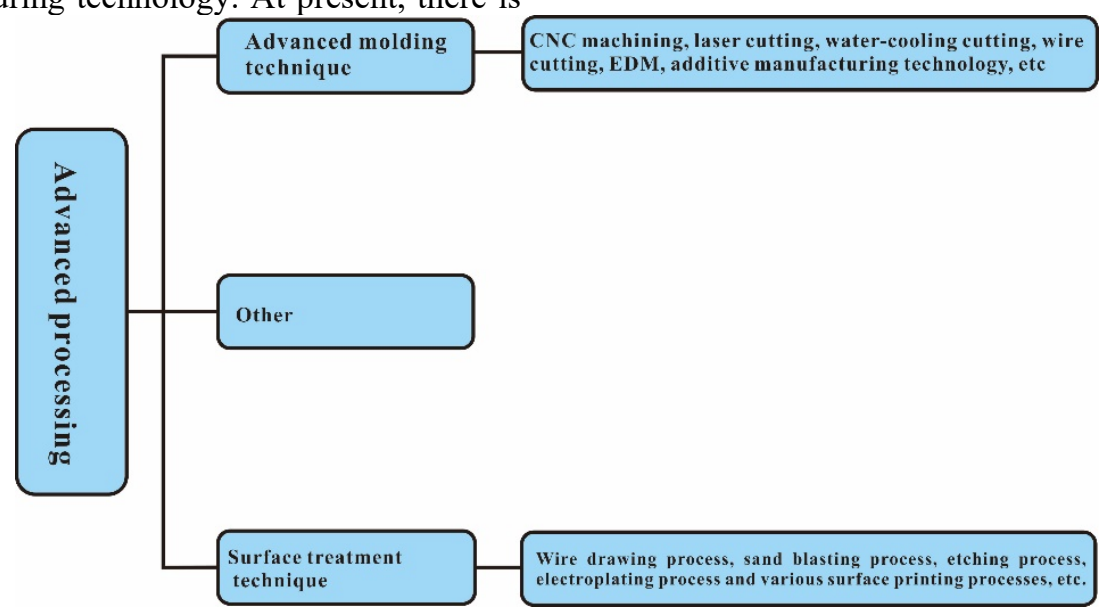

Figure 2. Schematic diagram of advanced processing technique

\subsection{Characteristics of modern advanced processing technique}

As far as design disciplines are concerned, modern advanced processing techniques have two very important characteristics. The first is high production efficiency, and the second is the unique aesthetic characteristics. In the second half of the 19th century, arts and crafts movement rose in Europe, in which it started to carry out design improvement movement since the decline in design levels caused by the mass production of the Industrial Revolution. This movement is actually a process of competition and integration of science and technology, culture and art. Croce, an Italian aesthetician, no clear definition of modern advanced processing technology, because it is a dynamic and comprehensive discipline. Compared with the traditional processing technique, any processing technique with the characteristics of mechanization, electrification and automation can become the modern advanced processing technique. For example, the numerical control processing, laser cutting, water-cooling cutting, wire cutting, EDM, additive manufacturing technology in the molding process; the drawing process, sandblasting process, etching process, electroplating process and various surface printing processes of surface treatment etc. pointed out that "art and science are different and interrelated; they intersect aesthetically." The Pythagorean theorem in ancient China, the golden section rule, the invention of the periodic table of elements, the arrangement of the microscopic world, the mystery of biological DNA, etc., these highlights in the history of scientific development conform to the law of beauty and give people inspiration of beauty. ${ }^{[5]}$ These are representative works of modern science and technology aesthetics. As Ben Yaming said, mechanical reproduction a hot topic in the current international economic development and industrial research. Reproduction technology has brought the general public closer to art, and the popular way of acceptance has 
become the main of the art acceptance in the era of mechanical reproduction. ${ }^{[6]}$

This paper attempts to discover the beauty of science and technology presented by modern advanced processing technology by means of design and aesthetics.

\section{Cultural and creative product design}

In the context of globalization, cultural and creative industries meet people's spiritual and cultural needs. With the comprehensive combination of culture, art and economy, high technology, all media, and creativity, it provides the public with new industrial groups of culture, art, spirit and entertainment products. Due to the outstanding achievements made by the British in the creative industry, the cultural and creative industry has been regarded by Denmark, Australia, Japan, South Korea and other countries as the fourth economic wave after the third wave of information industry economy, which has become a hot topic in the current international economic development and industrial research. ${ }^{[7]}$

Cultural and creative products refer to the products or combinations of products produced in cultural and creative industries. In terms of the final form of products, cultural creative products contain two interdependent parts: cultural creative content and hardware carrier. Cultural and creative products are different from most general products, mainly reflected in its cultural and creative content, which is the core value of cultural and creative products. But the content of cultural creativity can not exist independently, it must depend on the specific hardware carrier. Therefore, the price of cultural and creative products is mainly composed of two parts: one is the cost of hardware carrier, the other is the spiritual and emotional value of cultural and creative content. The former is easy to quantify, while the latter is often difficult to quantify. ${ }^{[8]}$ In recent years, there have been many cultural and creative design competitions for intangible cultural heritage projects, which also provides a new idea for the protection of intangible cultural heritage .

\section{Innovation of iron painting - Baogong cultural and creative product development process}

Under the impact of the market economy, the iron painting intangible cultural heritage project in Wuhu City of Anhui Province has also developed in a recession in recent years. Wuhu Chushi iron painting arts and Crafts Co., Ltd. is a representative enterprise in Wuhu iron painting industry. In recent years, it has jointly established the Wuhu Iron Painting Forging Technique Vocational Education Base with Anhui Electromechanical Vocational and Technical College. The author has been cooperating with Wuhu Chushi Iron Painting and Handicraft Co., Ltd. The following is an overview of the development process of Baogong's cultural and creative products, an innovative iron painting.

\subsection{Cultural and creative content}

Cultural and creative products are from a deep understanding of cultural content. ${ }^{[9]}$ The classic characters are undoubtedly typical symbols of cultural circles. It not only has the cultural heritage, but also needs to conform to the demands of the new era. A classic character is shaped as a symbol of culture, which seems to have become a common means in cultural and creative product design.

This is a competition work collected by Anhui Institute of mechanical and electrical technology, which has reached the requirement of mass production in the later stage. Baogong is a typical symbol of integrity in Chinese culture, and there are many creations in this field. How to innovate this cultural symbol? It is the key of this re-creation. The author was inspired by a category of numerical control processing technology -wire cutting technology, and used the positive and negative shapes in the design to show Baogong's face with clear distinction between justice and evil. In this way, two patterns can be obtained in one processing, and the materials are not wasted; positive and negative shapes can also convey the concept of "Yin and Yang" in traditional Chinese culture; the concept of Yin and Yang also fits the Chinese folklore that Baogong " was always judging the cases day and night". This positive and negative, Yin and Yang concept also conveys criminals that has "nowhere to escape".

\subsection{Iron painting hardware carrier}

Traditional iron painting mainly relies on manual forging, with small scope; in recent years, the concept of "innovative iron painting" has gradually emerged in the iron painting industry. Innovative iron painting mainly refers to iron crafts which are different from traditional iron paintings such as manual forging, rough freehand brushwork, monotonous colors, and single materials. and so on. In the creation process of Baogong iron painting, we mainly use the wire cutting technology of numerical control processing technology, so it also belongs to the category of innovative iron painting.

\subsection{Development process}

5.3.1. Convert raster to vector. Consult the literature and find the appropriate grid map Baogong pattern (Figure 3); guide the grid into the CorelDraw software and draw lines for vector (Figure 4). At this time, it should be noted that the regular pattern is a complete Bezier curve around. 


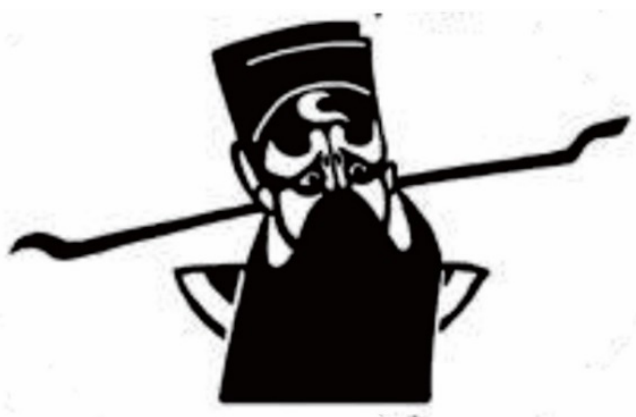

Figure 3. grid graphics Baogong pattern

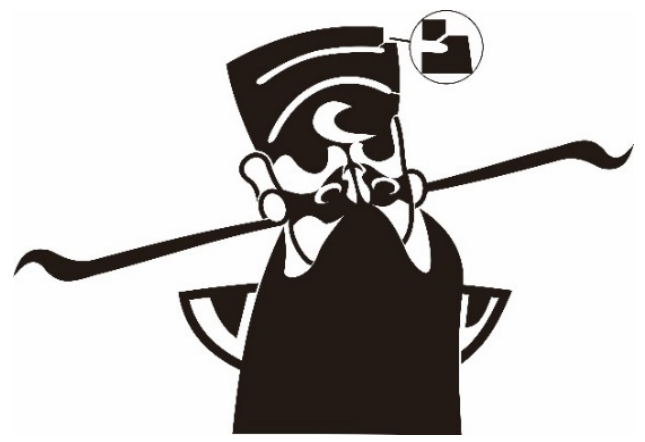

Figure 4. vector drawing graphics of Baogong pattern

5.3.2. Converting vector graphics into a format recognized by wire cutting technology. The final vector graphics generated in the CorelDraw software is in CDR format, which is a complete Bezier curve (Figure 5); the CDR format is imported into AutoCAD software and converted into a DWG format recognized by wire cutting technology.

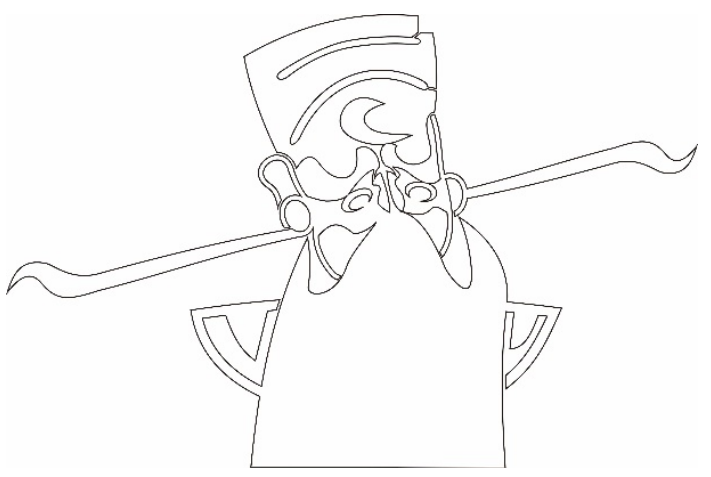

Figure 5.CDR format (a complete Bezier curve)

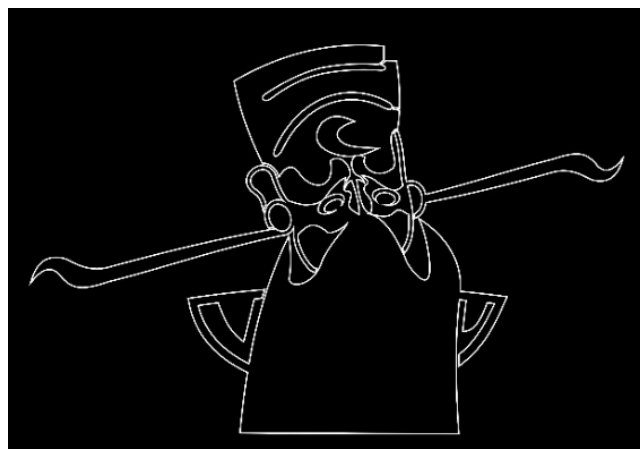

Figure 6. DWG format (format recognized by wire cutting technology)
5.3.3. Preparation of materials and processing equipment. The biggest feature of the wire cutting technology is that it can process small and complex work pieces, the minimum diameter of electrode wire can reach $0.01 \mathrm{~mm}$, and it can process fine structures such as narrow gap and sharp angle (small fillet radius). This feature enable our cultural and creative products to have the characteristics of one size cutting and positive and negative shape.

The material is 10 of 304 stainless steel wire cutting special steel plates with a size of $295 * 200 * 1.2(\mathrm{~mm})$; the processing equipment is Mitsubishi slow-moving wire MV1200S cutting special equipment.

5.3.4 Import of files and processing of work pieces. First, align and fix 10 steel plates on the piercer with fixtures, customize the origin of cutting at the appropriate position, drill out the cutting origin with the piercer, then move the steel plates and clamps to a proper position of the wire cutting machine; import the DWG file into the wire cutting equipment, debug the control system on the wire cutting equipment; start the control system and start cutting.

After processing, unload the work piece, polish and acidify it, then spray the surface with black automatic paint; finally mount it. Figure 7 shows the separated positive and negative shapes after unloading the work piece.
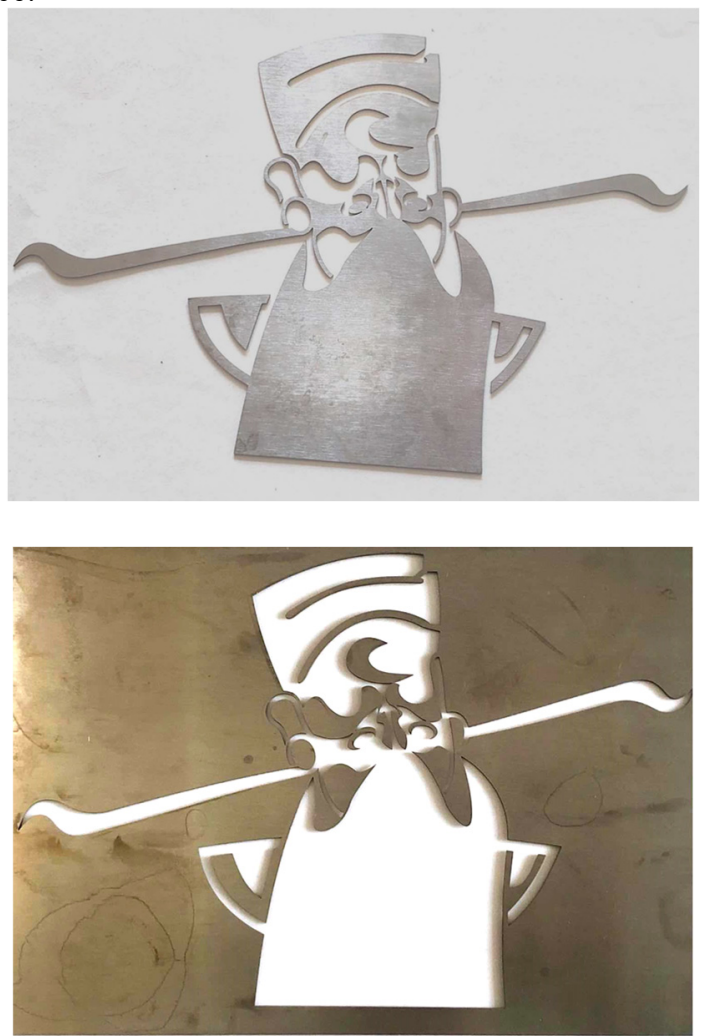

Figure 7. positive shapes (on the left) and negative shapes (on the right) separated after cutting 


\section{Conclusion}

This cultural and creative product design won the first prize in the honest and integrity cultural collection in school, which also received widespread attention and praise from the field. It enriches the connotation of iron painting, and also expands the development channels of iron painting. It is a more successful exploration. It explains the connotation of the unity of technology and art, expounds the internal consistency of technology and aesthetics, shows the vitality of traditional intangible cultural heritage, and displays the infinite charm of technology aesthetics. Real creative design must be influenced by technology and art, supported by technology, and it breeds a strong product of artistic appeal. Technology and art are not mutually exclusive and antagonistic, but mutual, interactive and symbiotic. The profound connection and combination of technology and art form a language of human beings in history. ${ }^{[10]}$ Inheritance and innovation are the common problems faced by many intangible cultural heritage projects. Taking intangible cultural heritage projects as the foundation, cultural and creative product design as the carrier, we need to make efforts to improve the processing technique by using modern scientific and technological means in the future.

\section{References}

1. Zhang Suxia.(2014).Research on evaluation model construction and protection system of intangible cultural heritage protection of traditional handicrafts based on stakeholder theory.Beijing: Beijing Jiaotong University.

2. Wu Shan, Zhang Ying. (2019).On the promotion of standards in the productive protection of intangible cultural heritage of traditional handicrafts. China Quality and Standards Guide, 2019(03): 44-47.

3. Sun Yayun, Wang Fan. (2019).Research on the design of intangible cultural heritage traditional handicrafts and creative products. Development and Innovation of Electromechanical Products, 2019(03): 48-50.

4. Zhang Yin.(2017). On the development of cultural and creative products based on the artistic characteristics of "non-legacy" products. Chinese Business Review, 2017(13): 134-137.

5. Liu Guijie.(2008).Chang Chengliang. Integration of technology aesthetics and aesthetics. Innovation and Technology, 2008(02): 22-23.

6. Le Rongrong.(2017).The relationship between technology and art-An analysis of Ben Yaming's

"Art Works in the Age of Mechanical Reproduction" . Anhui Literature, 2017(10): 56-57.

7. Liu Jing. (2017).On sensory communication of cultural and creative product. Fujian Forum Humanities and Social Sciences Edition, 2017(10): 82-89.
8. Wei Pengju,(2010). Attributes and characteristics of cultural and creative products. Culture Monthly, 2010 (08): 51-53.

9. Zhu Honghong, Lou Li, Gu Yuan. (2018). Research on cultural and creative product design integrated into Yangzhou culture- Taking "Qingyun Yangzhou" cultural and creative product design as an example. Design, 2018(04): 124- 125.

10. Li Lixin. (2002). originally born with the same roots - On the relationship between technology and art . Journal of Suzhou University (Engineering Science Edition), 2002(6): 7-10. 